\title{
Functional diversity of reproductive traits increases across succession in the Atlantic forest
}

\author{
Bianca Warring ${ }^{1}$, Fernanda Cristina Gil Cardoso ${ }^{2}$, Marcia C.M. Marques ${ }^{2}$ \& Isabela Galarda Varassin ${ }^{2,3}$
}

\begin{abstract}
Niche and neutral processes shape community assembly with a possible shift of niche and neutral importance in communities undergoing temporal changes during succession. Functional diversity helps to discriminate assembly processes since trait distribution is dependent on those processes. We evaluated the changes in reproductive traits related to pollination and seed dispersal in a successional gradient in an Atlantic Forest area, Southern Brazil. We surveyed forests undergoing regeneration varying in age from 2 to 80 years after pasture abandonment. We expected an increase in functional diversity of reproductive traits and a greater role of limiting similarity across succession. Abiotic and mixed pollination systems, dioecious sexual system, biotic dispersed, many-seeded and small-seeded species decreased as the forest got older. Conversely, bee-pollinated, bell-shaped, small and androgynous flowers increased across forest succession as well biotic dispersed and large-seeded species. Functional richness and functional dispersion were higher in older forests. Changes in functional diversity were positively related to species richness, indicating that species enrichment in older forests added new sets of reproductive traits. These changes in trait distribution and functional diversity across succession in the Atlantic Forest suggest an increased role of biotic interactions and limiting similarity process structuring plant assemblages of second-growth tropical forests.
\end{abstract}

Key words: dispersal, functional dispersion, pollination, forest regeneration, functional richness.

\section{Resumo}

As florestas apresentam um enriquecimento gradual de espécies e um aumento em complexidade estrutural e funcional durante a sucessão. Este trabalho caracterizou os traços reprodutivos de plantas relacionados à polinização e à dispersão em um gradiente sucessional, em uma área de Mata Atlântica, Sul do Brasil. O levantamento das espécies foi realizado em áreas florestais sucessionais oriundas de regeneração natural, em idades variando entre 2 e 80 anos após o abandono da pastagem. Houve predominância de flores polinizadas por abelhas, abertas, hermafroditas e que disponibilizam o pólen como em todos estádios sucessionais. Os sistemas de polinização abiótico e misto, sistema sexual dióico, espécies com dispersão abiótica, com muitas sementes e sementes pequenas diminuíram com a idade das florestas. Espécies polinizadas por abelhas, flores com corola funil/sino, como de corola pequena e andróginas assim como espécies dispersas bioticamente e com sementes grandes aumentaram no gradiente sucessional. A riqueza funcional e a dispersão funcional aumentaram no gradiente sucessional. As mudanças da diversidade funcional foram relacionadas com o aumento da riqueza de espécies indicando que o enriquecimento de espécies em florestas mais velhas adicionou novos conjuntos de traços reprodutivos. Estas mudanças de distribuição de traços e de diversidade funcional no gradiente sucessional sugerem um incremento do papel de interações bióticas na estruturação de assembleias de plantas de florestas tropicais secundárias.

Palavras-chave: dispersão, dispersão funcional, polinização, regeneração natural, riqueza funcional.

\footnotetext{
${ }^{1}$ Universidade Federal do Paraná, Programa de Pós-graduação em Botânica, Depto. Botânica, Centro Politécnico, C.P. 19031, 81531-980, Curitiba, PR, Brasil.

${ }^{2}$ Universidade Federal do Paraná, Laboratório de Ecologia Vegetal, Depto. Botânica, Centro Politécnico, C.P. 19031, 81531-980, Curitiba, PR, Brasil.

${ }^{3}$ Author for correspondence: isagalarda@gmail.com
} 


\section{Introduction}

There is a large debate on the relative importance of niche and neutral processes to community assembly. Functional traits are the currency of assembly, as stated by Weiher et al. (2011) and functional diversity may help to discriminate assembly processes (Mouchet et al. 2010). Niche filtering processes result in a similar composition of species traits due to environmental filters (Zobel 1997). Limiting similarity processes result in a dissimilar composition of species traits due to coexistence of dissimilar competitive species (MacArthur \& Levins 1967; Chesson 2000). Neutral theory posits that community assembly occurs irrespective of trait distribution (Hubbel 2001). There are some modulatory effect of species traits or habitat on the balance of niche and neutral importance to community assembly. Species traits as dispersal capabilities of species or absence of regeneration niches, for example, are positively related to neutrality (Weiher et al. 2011). For example, neutral processes are important in early successional communities and tend to give space to niche-based processes in plant communities undergoing temporal changes under succession (Chu et al. 2007). There is a growing interest on trait-environment relationships based on trait dispersion across an environmental gradient (Weiher et al. 2011).

Perturbations in a forest result in changes in forest composition and structure over time (Chazdon 2008). During succession, forests experience a gradual increase in richness and in structural complexity until the old-growth stage, which can take hundreds of years (Wirth et al. 2009; Chazdon 2012). These changes in species composition result in changes of plant reproductive traits (Chazdon et al. 2003; Chazdon 2008). It is known that species diversity and functional diversity of vegetative traits tend to increase during succession of secondary forests $(\mathrm{Bu}$ et al. 2014; Lohbeck et al. 2012). It is also known that functional diversity of reproductive traits differs among forested and deforested areas (Mayfield et al. 2005) and that reproductive trait distribution changes during succession (Chazdon et al. 2003; Chazdon 2008). However, little is known about changes in functional diversity of reproductive traits during sucession of tropical secondary forests.

Plant-pollinator interactions are important to the community structure. Nevertheless, most studies about plant-pollinator interactions tend to focus on a single species or a plant guild and its pollinators, and neglect the community context where those interactions are embedded (Waser et al. 1996; Albrecht et al. 2010; Freitas et al. 2014). The distribution of some reproductive traits was already associated to community assembly processes (Eaton et al. 2012). In this sense, research on reproductive traits is useful to the understanding of conservation of natural habitat under fragmentation and under successional processes (Machado \& Lopes 2004; Girão et al. 2007) and may also help restoration management (Garcia et al. 2015). Indeed, plant-pollinator and plant-disperser interactions have a central role in the community structure since the outcome of these interactions may influence species spatial distribution, richness and abundance, as well as the trophic structure and community phenodynamics (Janzen 1970; Smith 1973; Heithaus 1974; Bawa et al. 1985; Yamamoto et al. 2007).

Flower and fruit shape, color and size are traits associated to the establishment of specific interactions (Faegri \& van der Pijl 1979; Herrera 2002; van der Pijl 1982). It is expected that they might shape community assembly patterns (Sargent \& Ackerly 2008; Freitas et al. 2014) in a successional gradient. Floral morphology may exclude or attract specific floral visitors and pollinators, specially those associated to animal sensorial capacities to distinguish and memorize visual and olfactive patterns (Chittka et al. 2001; Gegear \& Laverty 2001; Machado \& Lopes 2004). Floral size and resources available may constrain pollinators (Feinsinger \& Colwell 1978; Frankie et al. 1983; Armbruster et al. 1994; Machado \& Lopes 2004). In the same way as in pollination, fruit characteristics such as size and color are associated to dispersal mode and dispersers (Wheelwright 1985; Flörchinger et al. 2010; Galetti et al. 2011; Cazetta et al. 2012). Among the ecological processes shaping community structure (facilitation, competition and filtering), floral color diversity organizes alpine meadow communities through facilitation (McEwen \& Vamosi 2010), and floral resource, size, color and shape are probably limiting the similarity among montane co-occurring species due to reproductive competition (Eaton et al. 2012).

There is a growing concern about which functions are performed by each set of functional trait, a key question when studying functional diversity and ecosystem functioning (Diaz \& Cabido 2001; Petchey \& Gaston 2006). A framework 
for the inclusion of reproductive traits in studies on community assembly was proposed by Sargent \& Ackerly (2008) and further developed by Freitas et al. (2014). Little is known about the most important reproductive traits involved in assemblages undergoing changes during the succession of tropical forests. In this study we present a first step in understanding the distribution of reproductive traits and functional diversity across succession in the Atlantic forest. We assessed the variation of reproductive traits of woody plants occurring in a successional gradient of Atlantic Forest in southern Brazil. A predominance of bees and traits related to bee pollination are expected since bees are known as the major pollinators in tropical areas (Bawa 1990; Ramirez \& Brito 1992; Martins \& Batalha 2007). A predominance of biotic dispersal system and traits related to biotic dispersal are expected since this dispersal system is more common in Atlantic forests (Yamamoto et al. 2007; Liebsch et al. 2008). The importance of biotic pollination and dispersal indicates that niche-based factors are important when considering reproductive traits in shaping the temporal organization of communities. This was reported for flower traits controlling plant communities across restoration stages (Garcia et al. 2015) and seed traits controlling nucleation patch colonization in Araucaria forests (Duarte et al. 2007). Besides that, it is expected that these traits change across successional gradients with an increased importance of niche-based factors (Duarte et al. 2007), specifically it is expected a shift from stronger environmental filtering in youger forests to stronger competition interactions in older forests, leading to limiting similarity (Lohbeck et al. 2014). As for the reported increase in functional diversity of vegetative traits along succession (Lohbeck et al. 2012), a parallel increase of functional diversity of reproductive traits is expected due to changes in the distribution of reproductive traits.

\section{Methods}

\section{Study area}

The study was carried out in Reserva Natural Rio Cachoeira (RNC, 25 $19^{\prime} \mathrm{S}$ and $48^{\circ} 42^{\prime} \mathrm{W}$ ) and Reserva Natural Morro da Mina (RNMM, 25 $21^{\circ} \mathrm{S}$ and $48^{\circ} 46^{\circ} \mathrm{W}$ ), both inserted in a protected area in the municipality of Antonina, Paraná, Southern Brazil. The natural reserves are property of the local NGO Society for Wildlife Research and Environmental Education (SPVS). The reserves include old growth forests and areas in a process of natural regeneration, and in different successional stages after the abandonment of agricultural and cattle farming activities (Ferretti \& Britez 2006). The reserves are within the domain of the Atlantic Forest (Veloso et al. 1991), with Submontane, Lowland and Alluvial sub-formations. The region is predominantly covered by forests $(83 \%$ of total area), which indicates a good conservation condition (Kauano et al. 2012). The old-growth $(68.6 \%)$ and secondary forests $(9.5 \%)$ are the most representative classes, while grazing areas $(4.2 \%)$ and bare soil areas $(<1 \%)$ are less common (Kauano et al. 2012). The climate, according to Köppen classification, is humid mesothermal subtropical (Cfa), with an average temperature of $20.6{ }^{\circ} \mathrm{C}$, mean annual precipitation of $2,517 \mathrm{~mm}$, without defined dry season and infrequent frosts (IPARDES 2001).

Sample design and vegetation survey

The study consisted of a vegetation survey in successional forest areas derived from natural regeneration after interruption of cattle farming in different periods (2-80 years after interruption). A total of 53 circular plots (14m radius; 47 in RNC and 6 in RNMM) were randomly distributed along the two reserves, comprising 2-3, 4-5, 6-7, 8-10, 15-25, 30-50 years (eight plots for each age category), and $>80$ years (five plots) after the abandonment. There were fewer plots in the older age due to the difficulty in finding areas that represent this category. The plots were selected based on pre-existing carbon-monitoring plots, which were established using an overlap of aerial photographs, vegetation maps, soil and land use maps in order to optimize the restoration activities and management of the reserves. The selected plots, therefore, represent a successional and edaphic gradient of the study region, and were placed at least $500 \mathrm{~m}$ apart from each other. The plots were distributed in different conditions of soil (Cambisol Gleysol) and relief (lowland and hillsides; Ferretti \& Britez 2006; Liebsch et al. 2007; Cheung et al. 2010). The ages of these forests were previsously determined by the area managers (SPVS) based on cartographic base orthophotos (scale 1:5000) and a plain-altimetrical map (scale 1:25,000) of vegetation and soils, as well as interviews with local people (Ferretti \& Britez 2006). All areas between 2 and 30 years old were clear-cut and used for grazing during a 10-20 years before their abandonment for natural regeneration. Older regeneration areas (30-80 years old) suffered a lower impact, mainly due to selective logging. 
In each $14 \mathrm{~m}$ radius plot, we sampled all trees with diameter at breast height $(\mathrm{DBH} ; 1.3 \mathrm{~m}) \geq 5$ $\mathrm{cm}$. In a smaller concentric sub-plot (4 m radius), we measured all individuals with $\mathrm{DBH}<5.0 \mathrm{~cm}$ and height $\geq 1.30 \mathrm{~m}$ (or stem base diameter, for shrubs). Individuals with multiple basal stems were included when at least one of the stems had DBH $\geq$ $5.0 \mathrm{~cm}$. For each individual we recorded diameter at breast height $(\mathrm{DBH}$, at $1.30 \mathrm{~m})$, and species identification. We calculated total tree abundance and species richness for each plot, both for the $4 \mathrm{~m}$ and the $14 \mathrm{~m}$ radius. Detailed results of the vegetation survey can be found in Cardoso (2014).

Classification of the reproductive traits

We analyzed flowers and fruits for each species found inside the plots, and categorized reproductive traits related to dispersal and pollination. The ones related to pollination were pollination system, floral biology (size, type and floral resource), sexual system and flower resource offered for pollinators (Tab. 1). The analysis of these traits was based in three flowers for each species taken from herbarium specimens (Herbarium of the Botany department, Federal University of Paraná - UPCB) collected in the study areas, or from the literature. From these flowers we measured mean corolla size (height and width) which we later used to classify the corollas as inconspicuous $(\leq 4 \mathrm{~mm})$, small $(>4$ $\mathrm{mm}$ and $\leq 20 \mathrm{~mm}$ ) or large ( $>20 \mathrm{~mm}$; adapted from Girão et al. 2007). The pollination systems were based in Freitas \& Sazima (2006) and Girão et al. (2007). Some species may present more than one pollination system described in case studies available in the literature (Appendix 1). The type of flower (achlamydeous; inconspicuous, bell, brush, dish, flag, gullet and tube) was based on the criteria from Freitas \& Sazima (2006) and Girão et al. (2007). We described four categories of floral resources (nectar, nectar/pollen, pollen, absent), according to the literature (Appendix 1).

For the sexual systems, we recorded the presence of stamens and pistils, supplemented with literature information. For the dioecious species, we obtained trait information by analyzing samples of female flowers, except for Citharexylum myrianthum, Cordiera concolor, Mollinedia schottiana, Pausandra morisiana and Tetrorchidium rubrivenium, for which we used male flowers, since we did not have access to female flowers.

Table 1 - Categorization of the reproductive traits of plants.

\begin{tabular}{|c|c|}
\hline Traits & Category \\
\hline \multicolumn{2}{|l|}{ Pollination } \\
\hline Pollination System & $\begin{array}{l}\text { Abiotic; Bats; Bees; Hummingbirds; Beetles; Butterflies; Diverse small insects (DSIs); } \\
\text { Flies; Mixed; Moths; Wasps }\end{array}$ \\
\hline $\begin{array}{l}\text { Corolla size } \\
\text { (height and width) }\end{array}$ & Inconspicuous $(\leq 4 \mathrm{~mm}) ;$ Small $(>4 \mathrm{~mm}$ and $\leq 20 \mathrm{~mm}) ;$ Large $(>20 \mathrm{~mm})$ \\
\hline Floral resource & Nectar; Nectar/Pollen; Pollen; Absent \\
\hline Floral type & Achlamydeous; Brush; Bell; Dish; Flag; Gullet; Inconspicuous (flowers $\leq 4 \mathrm{~mm}$ ); Tube \\
\hline Sexual system & Andromonoecious; Dioecious; Hermaphrodite; Monoecious; Monodioecious \\
\hline \multicolumn{2}{|l|}{ Dispersal } \\
\hline Dispersal system & Abiotic; Biotic \\
\hline Fruit type & Fleshy; Infructescens; Dry \\
\hline Fruit color & Black/Purple; Brown; Green; Orange/Red; Yellow; White \\
\hline Fruit size & Small $(\leq 5 \mathrm{~mm}) ;$ Medium $(>5 \mathrm{~mm}$ and $\leq 15 \mathrm{~mm}) ;$ Large $(>15 \mathrm{~mm})$ \\
\hline Number of seeds per fruit & Few (up to 10$)$; Many (11 to $>100)$ \\
\hline Seed size & Small $(\leq 2 \mathrm{~mm}) ;$ Medium $(>2 \mathrm{~mm}$ and $\leq 15 \mathrm{~mm}) ;$ Large $(>15 \mathrm{~mm})$ \\
\hline
\end{tabular}


Reproductive traits related to dispersal were dispersal system, type, color and size of fruit, and size and number of seeds per fruit (Tab. 1). For the categorization of traits related to dispersal, fruit size, seed size and number of seeds per fruit, we used three fruit samples from herbarium specimens collected in the study areas, or from a reference collection from our laboratory. We followed Silva \& Tabarelli (2000) to categorize dispersal systems, and species traits were recorded from the literature (Appendix 1). The fruits were classified as Fleshy, Infructescense or Dry; fruit color was determined from the literature (Appendix 1), following Galetti et al. (2011). We recorded fruit length and width in order to designate size categories, always considering the larger dimension. Measurements from herbarium samples may underestimate fruit size, then they may have some bias. The seeds present in each fruit were counted.

Data available for reproductive traits related to pollination and dispersal were not uniform for

Table 2 - Relationship between plant reproductive traits and forest ages in areas of Atlantic Forest, southern Brazil. $\mathrm{N}=$ the number of species sampled for each reproductive trait. For pollination traits, we considered the Bonferroni corrected $\alpha=0.0045$, for dispersal traits, we considered the Bonferroni corrected $\alpha=0.0071$.

\begin{tabular}{|c|c|c|}
\hline Traits & $U$ or $F$ test & $\mathbf{P}$ \\
\hline \multicolumn{3}{|l|}{ Pollination system, $N=176$} \\
\hline Abiotic & $U_{6}=26.41$ & 0.002 \\
\hline Bees & $U_{6}=27.82$ & 0.001 \\
\hline Flies & $r^{2}=0.20 ; F_{6,46}=3.21$ & 0.0102 \\
\hline Mixed & $U_{6}=29.88$ & $<0.0001$ \\
\hline Beetles, Butterflies, DSIs, Hummingbirds, Moths, Wasps & & NS \\
\hline \multicolumn{3}{|l|}{ Corolla Size, N = 155} \\
\hline Small & $r^{2}=0.41 ; F_{6,46}=7.03$ & $<0.0001$ \\
\hline Large, Inconspicuous & & NS \\
\hline \multicolumn{3}{|l|}{ Floral Resource, $N=119$} \\
\hline Nectar/Pollen & $U_{6}=27.48$ & 0.0002 \\
\hline Pollen, Nectar & & NS \\
\hline \multicolumn{3}{|l|}{ Floral type, $\mathrm{N}=165$} \\
\hline Bell & $U_{6}=38.41$ & $<0.0001$ \\
\hline Achlamydeous, Brush, Dish, Flag, Inconspicuous, Tube & & NS \\
\hline \multicolumn{3}{|l|}{ Sexual system, $N=188$} \\
\hline Dioecious & $U_{6}=20.17$ & 0.0026 \\
\hline Hermaphrodite & $U_{6}=27.79$ & 0.0006 \\
\hline Monoecious & & NS \\
\hline \multicolumn{3}{|l|}{ Dispersal system, $N=219$} \\
\hline Biotic & $U_{6}=17.93$ & 0.0064 \\
\hline Abiotic & $U_{6}=17.93$ & 0.0064 \\
\hline \multicolumn{3}{|l|}{ Fruit type, $N=216$} \\
\hline Dry, Fleshy, Infructescense & & NS \\
\hline \multicolumn{3}{|l|}{ Fruit color, $N=166$} \\
\hline Green & $U_{6}=20.16$ & 0.0026 \\
\hline Black/purple, Brown, Orange/Red, Yellow & & NS \\
\hline
\end{tabular}




\begin{tabular}{lll}
\hline Traits & $\boldsymbol{U}$ or $\boldsymbol{F}$ test & P \\
\hline Fruit Size, $\mathrm{N}=166$ & & \\
Small & $U_{6}=25.90$ & 0.0002 \\
Medium, Large & & $\mathrm{NS}$ \\
Number of seeds per fruit, $\mathrm{N}=171$ & & $<0.0001$ \\
Few & $U_{6}=27.94$ & $<0.0001$ \\
Many & $U_{6}=27.94$ & \\
Seed size, $\mathrm{N}=141$ & & 0.0023 \\
Small & $U_{6}=20.45$ & $\mathrm{NS}$ \\
Medium, Large & & \\
\hline
\end{tabular}

all species so the number of species representative of each reproductive trait was different (Tab. 2).

\section{Data analyses}

For each plot, we calculated the proportion of species presenting a given reproductive trait. The variation in the proportion of reproductive traits across forest ages was assessed by analysis of variance and we used Dunn's multiple comparison test for post-hoc comparisons. Traits with few data in forest age categories were not analyzed (flowers with no resource; andromonoecious and monodioiceous sexual systems). In order to control familywise error rate, we used the Bonferroni correction and we replaced the significance level, $\alpha=0.05$, by an adjusted level $\alpha^{\prime}=\alpha / k$ (Legendre $\&$ Legendre 1998). For pollination traits, we considered the Bonferroni corrected $\alpha=0.0045$, for dispersal traits, we considered the Bonferroni corrected $\alpha=0.0071$.

To explore different aspects of functional diversity, functional richness (FRic), functional dispersion (FDis) and functional evenness (FEve) were used as estimators of functional diversity (Laliberté \& Legendre 2010) and were calculated on R software (R Development Core Team 2013), with $F D$ package (Laliberté \& Legendre 2010). Functional dispersion (FDis) can handle qualitative traits, as the ones used here, to describe reproductive traits (Laliberté \& Legendre 2010). Functional dispersion is an interesting measure since it is not affected by richness because it is the mean distance in multidimensional trait space of individual species to the centroid of all species and it can shift the position of the centroid toward the more abundant species, when abundance is considered (Laliberté \& Legendre 2010).
Functional richness (FRic) estimates the dispersion of species in trait space (Villéger et al. 2008) and does not account for species abundance. Since it is calculated by the convex hull volume, which limits are defined by extreme values (Villéger et al. 2008), the occurrence of rare species with extreme traits can inflate FRic (Laliberté \& Legendre 2010). Functional evenness (FEve) describes the evenness of abundance distribution in a functional trait space (Villéger et al. 2008). FEve decreases either when abundance is less evenly distributed among species or when functional distances among species are less regular (Villéger et al. 2008). To evaluate the functional diversity on the successional gradient, a composition matrix was created with plots in rows and species abundance in columns, and a reproductive trait matrix was created, with species in rows and traits in columns. All traits were qualitative. Since many pollinator groups can be considered in a given plant species pollination system, this variable was transformed into a dummy variable. Both matrices were transformed in distance matrices applying Gower distance due to the presence of factor traits (Laliberte \& Legendre 2010).

To test if greater forest age implies in larger functional diversity, funcional richness (FRic), functional dispersion (FDis) and functional evenness (FEve), response variables, were related to forest age, predictor variable, we used analysis of variance, considering the Bonferroni corrected $\alpha=0.0167$. We used Tukey-Kramer multiple comparison test for post-hoc comparisons. To test if species richness results in larger functional diversity, functional richness (FRic), functional dispersion (FDis) and functional evenness (FEve), response variables, were related to species richness 
as a predictor variable, using linear regression analysis. We also considered the Bonferroni corrected $\alpha=0.0167$. To test if functional richness (FRic) results in larger functional dispersion (FDis) we used linear regression analysis.

\section{Results}

We sampled 221 species of trees and shrubs belonging to 59 families (Appendix 2). Species number increased across the successional gradient. The younger forests up to 10 years old had in average from 8 to 12 species and the older forest, 48 (Fig. 1; $r^{2}=0.85 ; F=49.25 ; \mathrm{DF}=6$, 46; $P<0.0001 ; \mathrm{q}=3.08)$.

Variation in the reproductive traits

Along the sucessional gradient, the pollination traits had higher proportions of species pollinated by bees $(74 \%)$ and small insects (25\%), androgynous flowers (54\%), dish-shaped $(55 \%)$ and small flowers $(55 \%)$, and pollen as

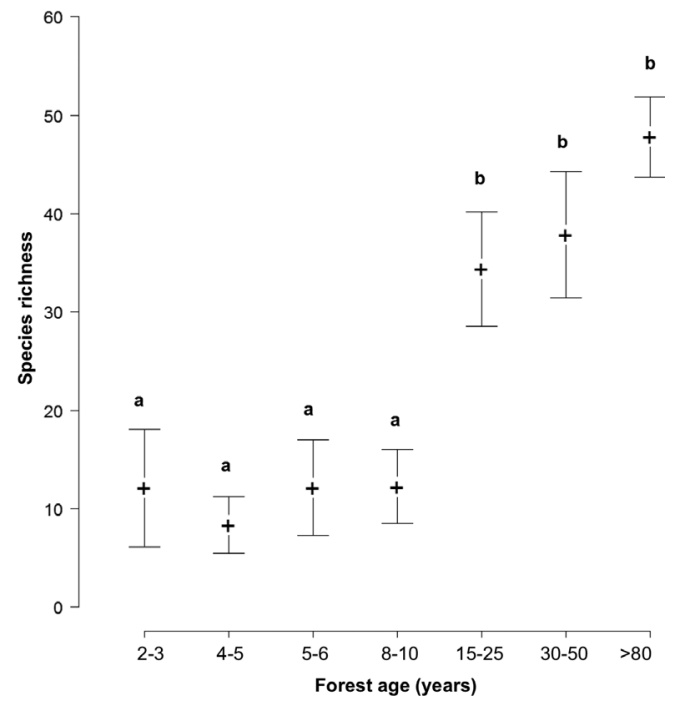

Figure 1 - Variation of species richness and forest age across a successional gradient in areas of Atlantic Forest, southern Brazil. Levels not connected by the same letter are signicantly different.
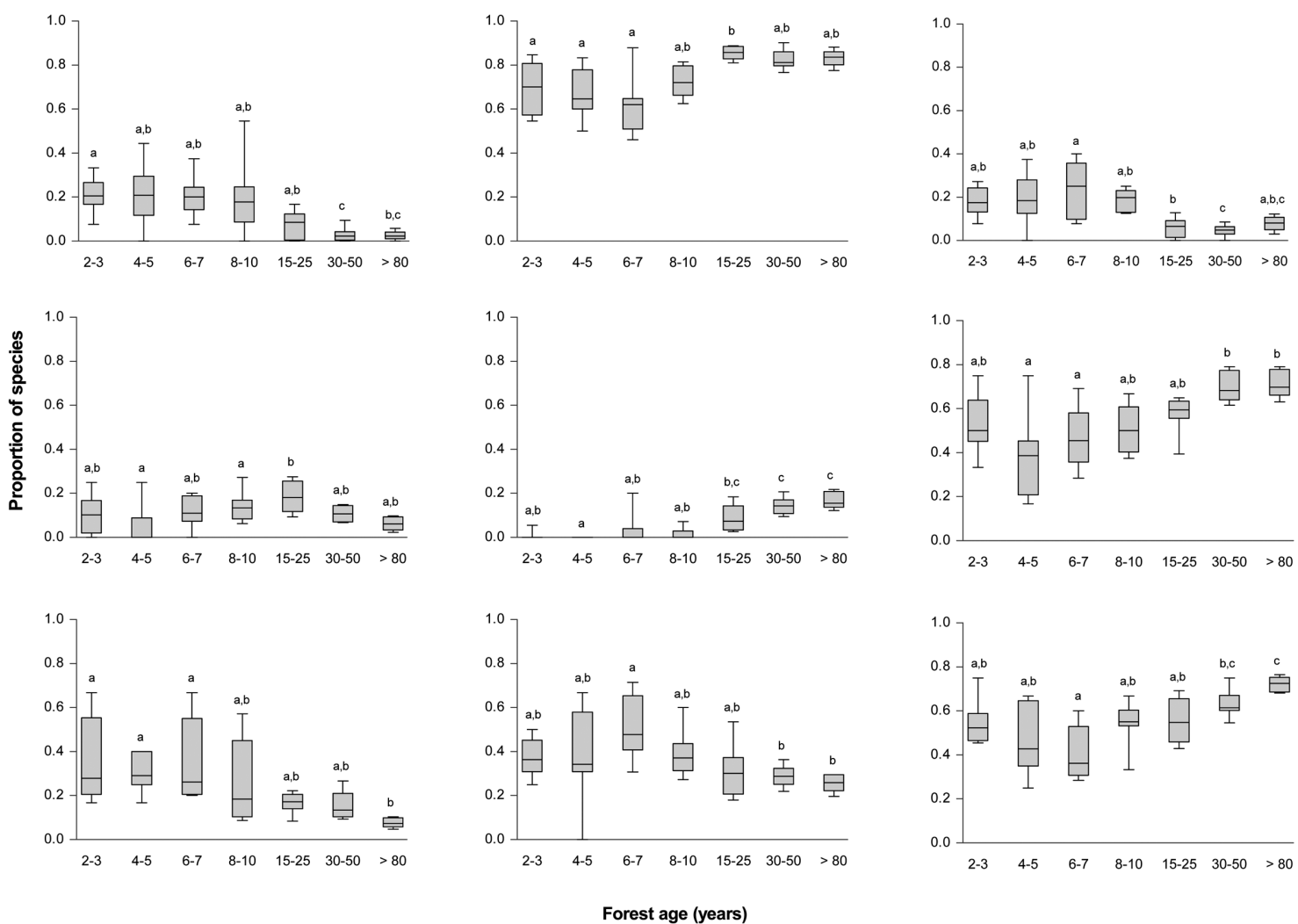

Figure 2 - Variation in the proportion of species with different reproductive traits related to pollination and forest age across a successional gradient, in areas of Atlantic Forest, southern Brazil - a. abiotic pollination system; b. bee pollination; c. mixed pollination; d. fly pollination; e. bell-shaped floral type; f. flower with small corollas; g. nectar and pollen as flower resource; h. dioecious sexual system; i. androgynous sexual system. Levels not connected by the same letter are signicantly different. 

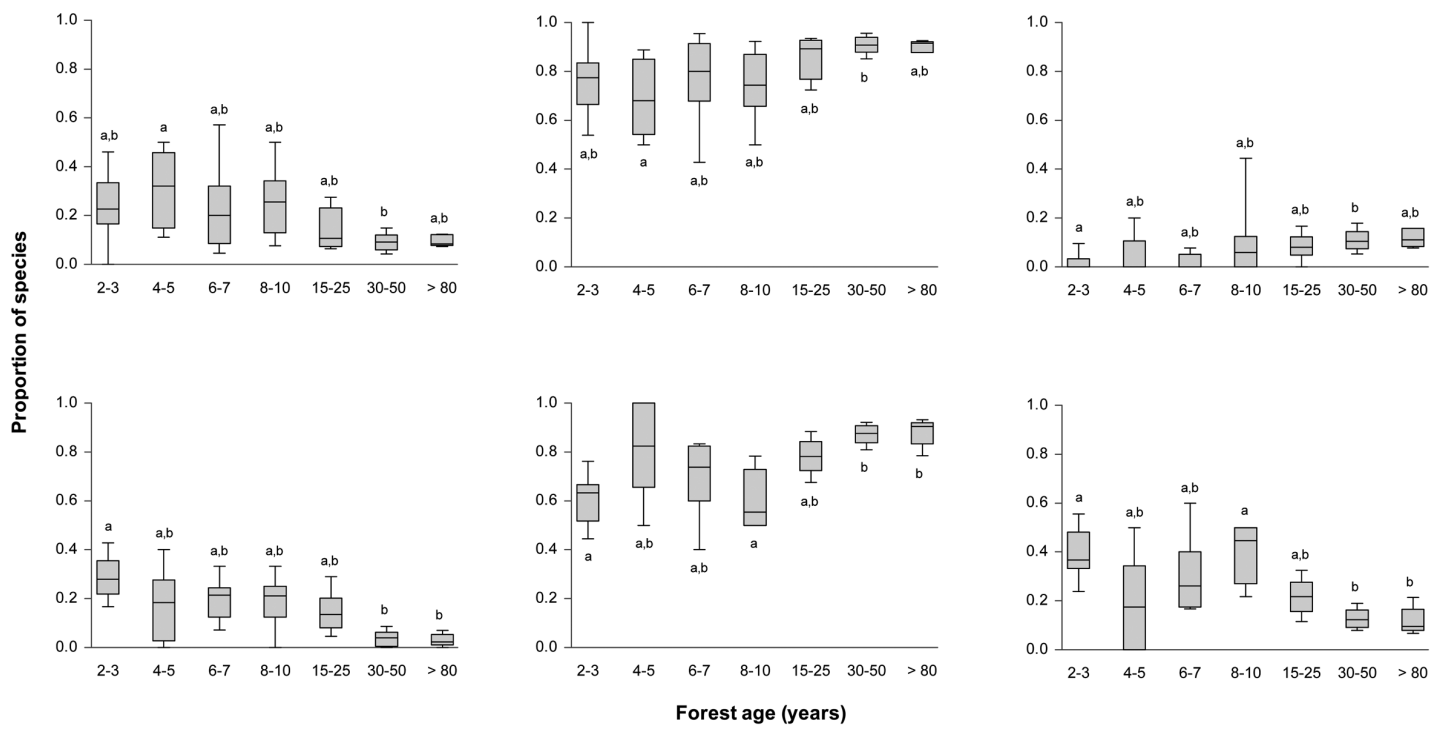

Figure 3 - Variation in the proportion of species with different reproductive traits related to dispersal and forest age across a successional gradient, in areas of Atlantic Forest, southern Brazil - a. abioitc dispersal; b. biotic dispersal; c. green fruits; d. small-sized fruits; e. many-seeded fruits; f. few-seeded fruits. Levels not connected by the same letter ar signicantly different.

the main resource to pollinators (53\%, Appendix $3)$. The dispersal traits had higher proportions of species with biotic dispersal $(80 \%)$, black or purple fruits $(36 \%)$, fleshy fruits $(54 \%)$ with medium-sized fruits $(53 \%)$, few seeds per fruit (74\%), and medium-sized seeds ( $76 \%$, Appendix 4). The proportions of some traits varied across sucessional ages (Tab. 2, Fig. 2,3), and the proportions of abiotic and mixed pollinated, dioecious species (Fig. 2), abiotic dispersed, many-seeded and small-seeded species (Fig. 3) were lower in older forests. On the other hand, the proportions of bee-pollinated species, bell-shaped flowers, with small corollas and androgynous (Fig. 2), as well biotic dispersed species were higher in older forests (Fig. 3).
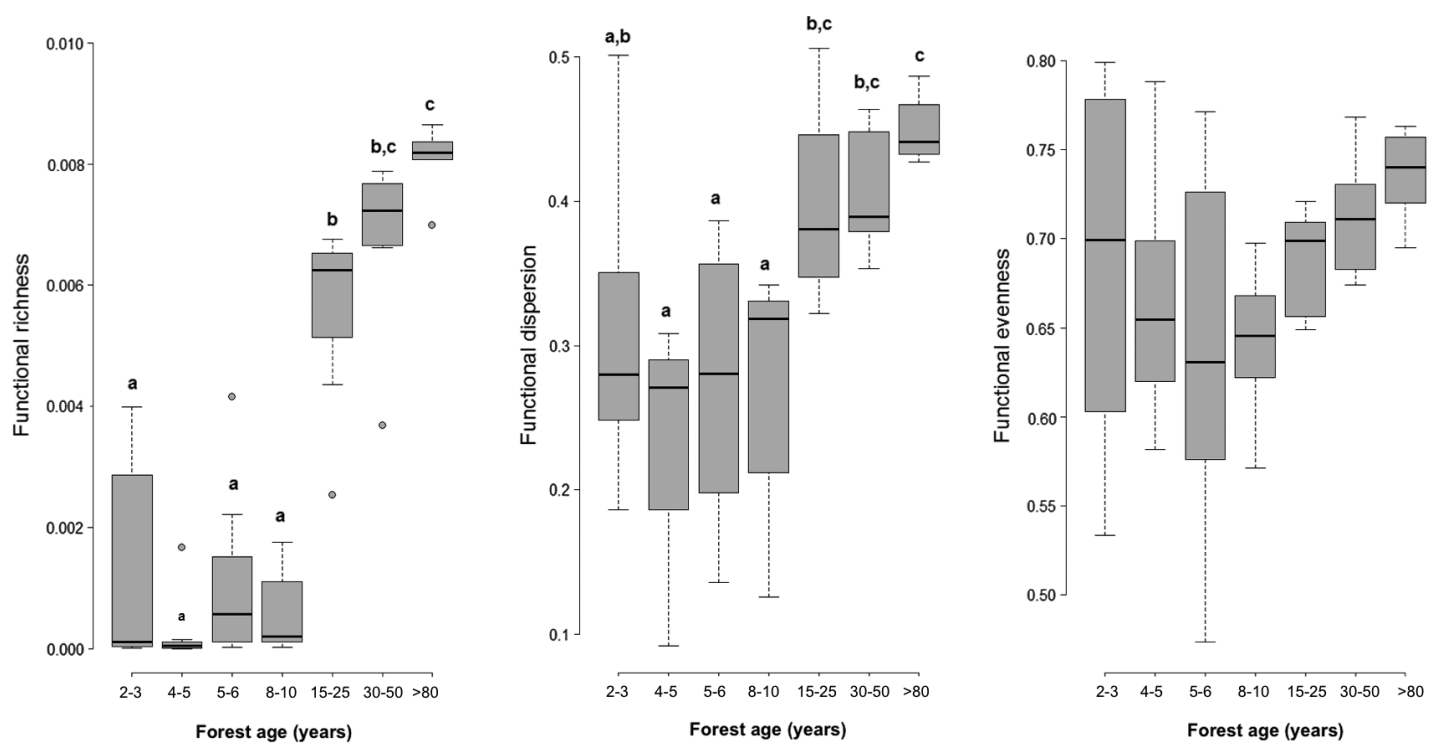

Figure 4-Variation on functional richness, functional dispersion and functional evenness and forest age across a successional gradient in areas of Atlantic Forest, southern Brazil. Levels not connected by the same letter are signicantly different. 

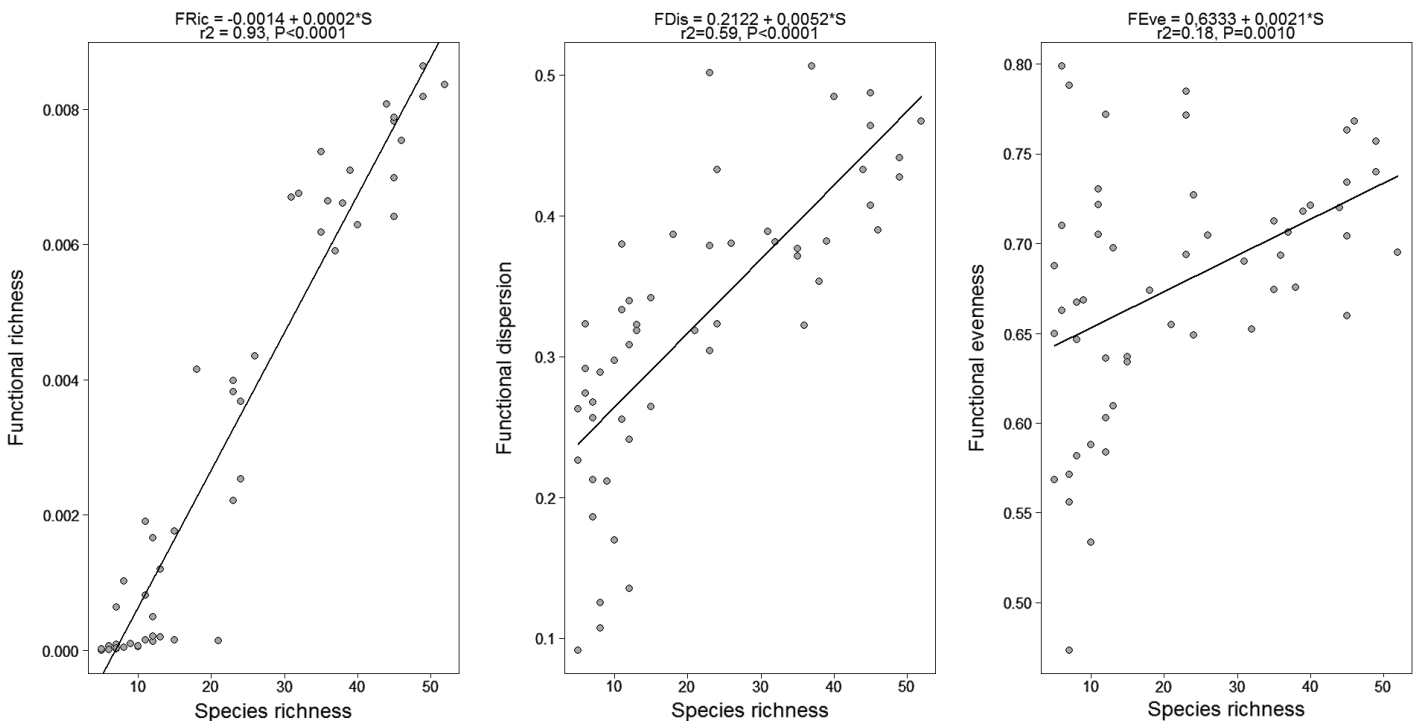

Figure 5 - Relationship between functional richness, functional dispersion and functional evenness and species richness across a successional gradient in areas of Atlantic Forest, southern Brazil.

\section{Functional diversity}

Functional richness (Fig. 4a) and functional dispersion (Fig. 4b) were similar among younger forests, up to 10 years old, and increased after 15 years (FRic: $H=40.08 ; \mathrm{DF}=6 ; P<0.0001 ; F D i s$ : $H=29.98 ; \mathrm{DF}=6 ; P<0.0001)$. The older forests, more than 80 years old, had the highest functional

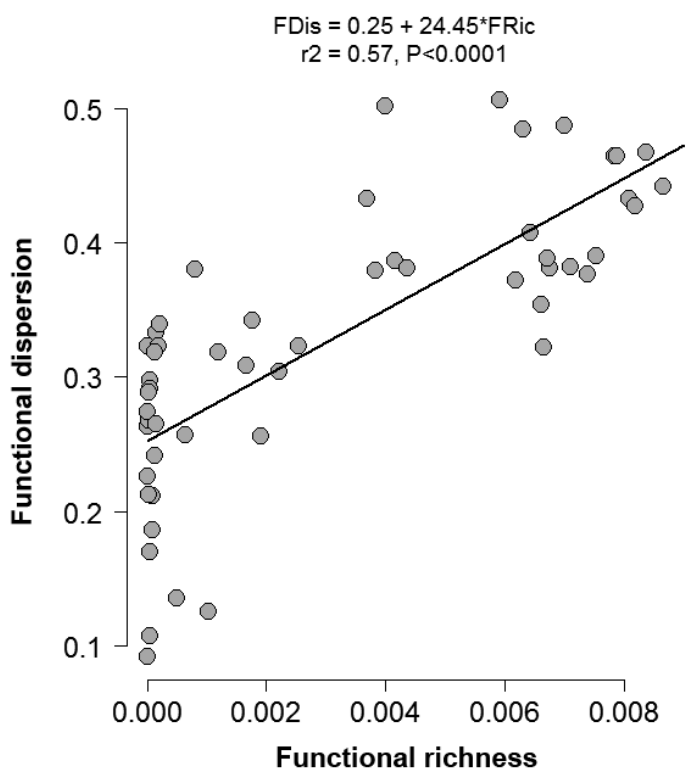

Figure 6 - Relationship between functional dispersion and functional richness in successional areas of Atlantic Forest, southern Brazil. richness and functional dispersion (Fig. 4a,b). Functional evenness (FEve) was similar across the successional gradient $(H=12.33 ; \mathrm{DF}=6 ; P$ $=0.05$ ), ranging from 0.47 to 0.80 (Fig. $4 \mathrm{c}$ ). All dimensions of functional diversity increased with species richness (Fig. $5 ;$ FRic: $r^{2}=0.93 ; F=674.27$; $\mathrm{DF}=1 ; 51 ; P<0.0001 ;$ FDis: $r^{2}=0.59 ; F=75.46$; $\mathrm{DF}=1 ; 51 ; P<0.0001 ;$ FEve: $r^{2}=0.18 ; F=12.21$; $\mathrm{DF}=1 ; 51 ; P=0.0010)$. Since we considered the Bonferroni corrected $\alpha=0.0167$, functional evenness variation was not explained by species richness. Finally, FDis increased with FRic $\left(r^{2}=\right.$ $0.57 ; F=69.91 ; \mathrm{DF}=1 ; 51 ; P<0.0001$; Fig. 6 ).

\section{Discussion}

Our study showed significant changes in traits distribution and functional diversity along the succession of the Atlantic Forest. The similarities of the distribution of reproductive traits across stages led to a high functional evenness. Functional richness and dispersion increase across successional stages suggests an increased role of biotic interactions in structuring plant assemblages of second-growth tropical forests.

The successional areas under study were characterized by a predominance of some reproductive traits. These similarities between many reproductive traits among successional areas may explain the similarities in functional evenness among forests since it measures the regularity of the distribution of the abundance in functional 
space (Mouchet et al. 2010). The high values of functional evenness ( 0.67 to 0.80 ) may be due to both filtering and limiting similarity processes, which have been reported to increase functional evenness (van der Plas et al. 2015). The similarities of distribution in reproductive traits also explain the high functional evenness since it will be maximized when species and abundance distributions are more even in the functional space (Mouchet et al. 2010). Among these traits, the predominance of bee pollination system was expected, as were the traits related to bee pollination system, pollen-flowers, dish-shaped corollas as well as the predominance of androgynous flowers. Diverse Small Insects (DSIs) pollination system was also predominant. The presence of DSIs may be due to the presence of many flowers with less restrictive morphology, such as dish-shaped corollas. Flowers with dishshaped corollas are visited by many different insects, such as bees, butterflies, moths, flies and wasps (Bawa 1990; Martins \& Batalha 2007). For dispersal traits, the predominance of biotic dispersal system was also expected, as were traits related to biotic dispersal systems, such as black fruits. Dry fruits were also well represented in the studied sites due to the large abundance of Alchornea and Tibouchina species.

As expected, functional diversity of reproductive traits increased with forest age, since both functional richness and functional dispersion were higher in older forests. The changes in functional richness and functional dispersion are related to changes in the distribution of traits. Younger forests tend to present more species with abiotic pollination system, dioecious sexual system and small-sized diaspores. Abiotic pollination and small-sized diaspores are probably traits related to a more neutral process of community assembly in the sense proposed by Weiher et al. (2011) due to a wider generalism compared to biotic pollinated and large-seeded species. Older forests tend to present more species with bell-shaped corollas and androgynous flowers. Large-seeded species are known to have a particular regeneration niche, which is a trait that should increase the role of niche-based process (Weiher at al. 2011). Thus, there are significant changes in forest functionality along Atlantic Forest succession for the areas under study. These changes in functional diversity were related to an increase in species richness in older forests, indicating that species enrichment in older forests added new sets of reproductive traits. Higher functional dispersion and richness may indicate a higher role of limiting similarity on assemblage organization (Mouchet et al. 2010) in older forests. This is in accordance with competitive driven establishment in older forests and a shift from stronger environmental filtering to stronger competition interactions as forests get older (Lohbeck et al. 2014).

At the successional areas under study, these changes in functional diversity are related to species with less accessible flower morphologies, such as species with bell-shaped corollas These traits have already been reported for more conserved forests in Atlantic Forest (Lopes et al. 2009), and may be interpreted as an indicator of conserved Atlantic forests (Garcia et al. 2015). This higher functional diversity indicates low redundancy in older forests, which may be driven by a higher role of limiting similarity in those forests. In this case species loss may have a higher impact on ecosystem functioning (Sazaki et al. 2009). Loss of interactions that are dependent on more restrictive flower morphologies, like the ones established by vertebrates and large invertebrates such as moths and large-sized bees (Faegri \& van der Pijl 1979) can be expected.

Our study showed significant changes in trait distribution and functional diversity, suggesting changing drivers across successional stages, with an increased role of limiting similarity. Besides that, the higher functional richness and dispersion in older forests indicate that long term changes in forest communities include diversification of reproductive traits. Reproductive trait divergence is thus a key driver for forest assembly and have to be taken into account in restoration practices. These findings should be considered in future actions of management and conservation of the Atlantic Forest.

\section{Acknowledgements}

To Sociedade de Pesquisa em Vida Selvagem e Educação Ambiental (SPVS) and their staff, for the access to maps and data, as well as logistical assistance in Rio Cachoeira and Morro da Mina Natural Reserves. To Leandro Freitas e Jana Magaly Tesserolli de Souza, for their suggestions to the first version of the manuscript, and Thais Bastos Zanata, for the help with the figures. To the Brazilian Research Council (CNPq), for partially sponsoring this study (Grant 577336/2008-8), for the grants to F.C.G.C., M.C.M.M (Grant 304650/2012-9), and I.G.V. (Grant 309453/20135). To the Brazilian Education Council (CAPES), for the grant to B.W. 


\section{References}

Albrecht, M.; Riesen, M. \& Schmid, B. 2010. Plantpollinator network assembly along the chronosequence of a glacier foreland. Oikos 119: 1610-1624.

Armbruster W.S.; Edwards M.E. \& Debevec E.M. 1994. Floral character displacement generates assemblage structure of western Australian triggerplants (Stylidium). Ecology 75: 315-329.

Bawa, K.S. 1990. Plant-pollinator interactions in tropical rain forests. Annual Review of Ecology, Evolution, and Systematics 21: 399-422.

Bawa, K.S.; Bulloch, S.H.; Perry, D.R.; Coville, R.E. \& Grayum, M.H. 1985. Reproduction biology of tropical lowland rain forest tree. II. Pollination system. American Journal of Botany 72: 346-356.

Bu, W.; Zang, R. \& Ding, Y. 2014. Functional diversity increases with species diversity along successional gradient in a secondary tropical lowland rainforest. Tropical Ecology 55: 393-401.

Cardoso, F.C.G. 2014. A estruturação de comunidades vegetais em áreas sucessionais da Floresta Atlântica em diferentes tipos de solo. Tese de Doutorado. Universidade Federal do Paraná, Curitiba. 139p.

Cazetta, E.; Galetti, M.; Rezende, E.L. \& Schaefer, H.M. 2012. On the reliability of visual communication in vertebrate-dispersed fruits. Journal of Ecology 100: $277-286$

Chazdon, R.L. 2008. In: Chance and determinism in tropical forest sucession. Carson, W.P. \& Schnitzer, S.A. (eds.). Tropical Forest Community Ecology. Wiley -Blackwell, Oxford. Pp. 384-408.

Chazdon, R.L. 2012. Regeneração de florestas tropicais. Boletim do Museu Paraense Emílio Goeldi. Ciências Naturais 7: 195-218.

Chazdon, R.L.; Careaga, S.; Webb, C. \& Vargas, O. 2003. Community and phylogenetic structure of reproductive traits of woody species in wet tropical forests. Ecological Monographs 73: 331-348.

Chesson, P. 2000. Mechanisms of maintenance of species diversity. Annual Review of Ecology and Systematics 31: 343-366.

Cheung, K.C.; Liebsch D. \& Marques M.C.M. 2010. Forest recovery in newly abandoned pastures in southern Brazil: implications for the Atlantic rain forest resilience. Natureza \& Conservação 8: 66-70.

Chittka, L.; Spaethe, J.; Schmidt, A. \& Hickelsberger, A. 2001. Adaptation, constraint, and chance in the evolution of flower color and pollinator color vision. In: Chittka, L. \& Thomson, J.D. (eds.). Cognitive ecology of pollination. Cambridge University Press, Cambridge. Pp. 106-126.

Chu, C.J.; Wang, Y.S.; Du, G.Z.; Maestre, F.T.; Luo, Y.J. \& Wang, G. 2007. On the balance between niche and neutral processes as drivers of community structure along a successional gradient: insights from alpine and sub-alpine meadow communities. Annals of Botany 100: 807-812.
Diaz, S. \& Cabido, M. 2001. Vive la différence: plant functional diversity matters to ecosystem processes. Trends in Ecology \& Evolution 16: 646-655.

Duarte, L.S.; Carlucci, M.B.; Hartz, S.M. \& Pillar, V.D. 2007 Plant dispersal strategies and the colonization of Araucaria forest patches in a grassland-forest mosaic. Journal of Vegetation Science 18: 847-858.

Eaton, D.A.R.; Fenster, C.B.; Hereford, J.; Huang, S-Q. \& Ree R.H. 2012. Floral diversity and community structure in Pedicularis (Orobanchaceae). Ecology 93: S182-S194.

Faegri, K.; van der Pijl, L. 1979. The principles of pollination ecology. Pergamon Press, Oxford. 244p.

Feinsinger, P. \& Colwell, R.K. 1978. Community organization among neotropical nectar-feeding birds. American Zoologist 18: 779-795.

Ferretti, A.R. \& Britez, R.M. 2006. Ecological restoration, carbon sequestration and biodiversity conservation: the experience of the society for wildlife research and environmental education (SPVS) in the Atlantic Rain Forest of southern Brazil. Journal for Nature Conservation 4: 249-259.

Flörchinger, M.; Braun, J.; Böhning-Gaese, K. \& Schaefer, H.M. 2010. Fruit size, crop mass, and plant height explain differential fruit choice of primates and birds. Oecologia 164: 151-61.

Frankie, G.W.; Haber, W.A.; Opler, P.A. \& Bawa, K.S. 1983. Characteristics and organization of the large bee pollination system in the Costa Rican dry forest. In: Jones, C.E. \& Little, R.J. Handbook of experimental pollination biology. Van Nostrand Reinhold Company Inc, New York. Pp. 411-447.

Freitas, L. \& Sazima, M. 2006. Pollination biology in a tropical high-altitude grassland in Brazil: interactions at the community level. Annals of the Missouri Botanical Garden 93: 465-516.

Freitas, L.; Vizentin-Bugoni, J.; Wolowski, M.; Souza, J.M.T. \& Varassin, I.G. 2014. Polinização e estrutura de comunidades. Biologia da Polinização. Projeto Cultural, Rio de Janeiro. Pp. 483-518.

Galetti, M.; Pizo, M.A. \& Morellato, L.P.C. 2011. Diversity of functional traits of fleshy fruits in a species-rich Atlantic rain forest. Biota Neotropica 11: 181-193.

Garcia, L.C.; Cianciaruso, M.V.; Ribeiro, D.B.; dos Santos, F.A.M. \& Rodrigues, R.R. 2015. Flower functional trait responses to restoration time. Applied Vegetation Science 18: 402-412.

Gegear, R.J. \& Laverty, T.M. 2001. The effect of variation among floral traits on the flower constancy of pollinators. In: Chittka, L. \& Thomson, J.D. (eds.). Cognitive ecology of pollination. Cambridge University Press, Cambridge. Pp. 1-20.

Girão, L.C.; Lopes, A.V.; Tabarelli, M. \& Bruna, E.M. 2007. Changes in tree reproductive traits reduce 
functional diversity in a fragmented Atlantic Forest landscape. Plos One 2: e908. DOI:10.1371/journal. pone.0000908.

Heithaus, E.R. 1974. The role of plant-pollinator interactions in determining community structure. Annals of the Missouri Botanical Garden 61: 675-691.

Herrera, C.M. 2002. Seed dispersal by vertebrates. In: Herrera, C.M. \& Pellmyr, O. (eds.). Plant-animal interactions: an evolutionary approach. Blackwell Publishing, Malden. Pp.185-208.

Hubbell, S.P. 2001. The unified neutral theory of biodiversity and biogeography. Princeton University Press, Princeton. 392 p.

IPARDES - Instituto Paranaense de Desenvolvimento Social. 2001. Zoneamento da Área de Proteção Ambiental de Guaraqueçaba. IPARDES, Curitiba. $150 \mathrm{p}$.

Janzen, D.H. 1970. Herbivores and the tree species in tropical forest. American Naturalist 104: 501-528.

Kauano, E.E.; Torezan, J.M.D.; Cardoso, F.C.G. \& Marques M.C.M. 2012. Landscape struture in the northern coast of Paraná state, a hotspot for the Brazilian Atlantic Forest conservation. Revista Árvore 36: 961-970.

Laliberté, E. \& Legendre, P. 2010. A distance-based framework for measuring functional diversity from multiple traits. Ecology 91: 299-305.

Legendre, P. \& Legendre, L. 1998. Numerical Ecology. Elsevier, Amsterdam. 853p.

Liebsch, D.; Goldenberg, R. \& Marques, M.C.M. 2007. Florística e estrutura de comunidades vegetais em uma cronosequência de Floresta Atlântica no Paraná. Acta Botanica Brasilica 21: 983-992.

Liebsch, D.; Marques, M.C.M. \& Goldenberg, R. 2008. How long does the Atlantic Rain Forest take to recover after a disturbance? Changes in species composition and ecological features during secondary succession. Biological Conservation 141: 1717-1725.

Lohbeck, M.; Poorter, L.; Martínez-Ramos, M.; RodriguezVelázquez, J.; van Breugel, M. \& Bongers, F. 2014. Changing drivers of species dominance during tropical forest succession. Functional Ecology 28: 1052-1058.

Lohbeck, M.; Poorter, L.; Paz, H.; Pla, L.; van Breugel, M.; Martínez-Ramos, M. \& Bongers, F. 2012. Functional diversity changes during tropical forest succession. Perspectives in Plant Ecology, Evolution and Systematics 14: 89-96.

Lopes, A.V.; Girão, L.C.; Santos, B.A.; Peres, C.A. \& Tabarelli, M. 2009. Long-term erosion of tree reproductive trait diversity in edge-dominated Atlantic forest fragments. Biological Conservation 142: 1154-1165.

MacArthur, R. \& Levins, R. 1967. The limiting similarity, convergence, and divergence of coexisting species. American Naturalist 101: 377-385.
Machado I.C. \& Lopes A.V. 2004. Floral traits and pollination systems in the Caatinga, a Brazilian Tropical Dry Forest. Annals of Botany 94: 365-376.

Martins, F.Q. \& Batalha, M.A. 2007. Pollination systems and floral traits in cerrado woody species of the Upper Taquari Region (Central Brazil). Brazilian Journal of Biology 66: 543-552.

Mayfield, M.M.; Boni, M.J.; Daily, G.C. \& Ackerly, D. 2005. Species and functional diversity of native and human-dominated plant communities. Ecology 86: 2365-2372.

McEwen, J.R. \& Vamosi, J.C. 2010. Floral colour versus phylogeny in structuring subalpine flowering communities. Proceedings of the Royal Society B 277: 2957-2965.

Mouchet, M.A.; Villéger, S.; Mason, N.W.H. \& Mouillot, D. 2010. Functional diversity measures: an overview of their redundancy and their ability to discriminate community assembly rules. Functional Ecology 24: 867-876.

Petchey, O.L. \& Gaston, K.J. 2006. Functional diversityback to basics and looking forward. Ecology Letters 9: 741-758.

R Development Core Team. 2013. R: a language and environment for statistical computing. R Foundation for Statistical Computing, Vienna, Austria: the $\mathrm{R}$ Foundation for StatisticalComputing. ISBN: 3-900051-07-0.

Ramirez, N. \& Brito, Y. 1992. Pollination biology in a palm swamp community in the Venezolana central plains. The Journal of the Linnean Society. Botany 110: 277-302.

Sargent, R.D. \& Ackerly, D.D. 2008. Plant-pollinator interactions and the assembly of plant communities. Trends in Ecology \& Evolution 23: 123-30.

Sazaki,T.; Okubo, S.; Okayasu, T.; Jamsran, U. \& Takeuchi, K. 2009. Two-phase functional redundancy in plant communities along a grazing gradient in Mongolian rangelands. Ecology 90: 2598-2608.

Silva, J.M.C. \& Tabarelli, M. 2000. Tree species impoverishment and the future flora ah the Atlantic forest of northeast Brazil. Nature 404: 72-74.

Smith, A.P. 1973. Stratification of temperate and tropical forest. American Naturalist 107: 671-683.

van der Pijl, L. 1982. Principles of seed dispersal in higher plants. $3^{\text {rd }}$ ed. Springer-Velag, Berlin. 218p.

van der Plas, F.; Janzen, H.; Ordonez, A.; Etienne, R.S.; Fokkema, W. \& Olff, H. 2015 . A new modeling approach estimates the relative importance of different community assembly processes. Ecology 96: 1502-1515.

Veloso, H.P.; Rangel-Filho, A.L.R.R. \& Lima, J.C.A. 1991. Classificação da vegetação brasileira, adaptada a um sistema universal. Instituto Brasileiro de Geografia e Estatística/IBGE, Rio de Janeiro. 124p. 
Villéger, S.; Mason, N.W.H. \& Mouillot, D. 2008. New multidimensional functional diversity indices for a multifaceted framework in functional ecology. Ecology 89: 2290-2301.

Waser, N.M.; Chittka, L.; Price, M.V.; Williams, N.M. \& Ollerton, J. 1996. Generalization in pollination systems, and why it matters. Ecology 77: 1043-1060.

Weiher, E.; Freund, D.; Bunton, T.; Stefanski, A.; Lee, T. \& Bentivenga, S. 2011. Advances, challenges and a developing synthesis of ecological community assembly theory. Philosophical Transactions of the Royal Society of London B: Biological Sciences 366: 2403-2413.

Wheelwright, N. 1985. Fruit-size, gape width, and the diets of fruit-eating birds. Ecology 66: 808-818.
Wirth, C.; Messier, C.; Bergeron, Y.; Frank, D. \& Fankhanel, A. 2009. Old-growth forest definitions: a pragmatic view. In: Wirth, C.; Gleixner, G. \& Heimann, M. (eds.). Old-growth forests: function, fate and value. Springer, New York. Pp. 11-33.

Yamamoto, L.F.; Kinoshita, L.S. \& Martins, F.R. 2007. Síndromes de polinização e de dispersão em fragmentos da Floresta Estacional Semidecídua Montana, SP, Brasil. Acta Botanica Brasilica 21: 553-573.

Zobel, M. 1997. The relative role of species pools in determining plant species richness: an alternative explanation of species coexistence? Trends in Ecology \& Evolution 12: 266-269. 